Trauma Surgery \& Acute Care Open

\title{
Incidence of acute respiratory distress syndrome and associated mortality in a polytrauma population
}

\author{
Karlijn J P van Wessem, Luke P H Leenen
}

Department of Trauma Surgery, University Medical Center Utrecht, Utrecht, The Netherlands

\section{Correspondence to Karlijn J P van Wessem,} Department of Trauma Surgery, University Medical Center Utrecht, Utrecht 3584 CX, The Netherlands; kwessem@ umcutrecht.n

This research was presented at the World Trauma Congress in San Diego on September 28, 2018.

Received 4 September 2018 Accepted 30 October 2018

\section{(c) Author(s) (or their} employer(s)) 2018. Re-use permitted under CC BY-NC. No commercial re-use. See rights and permissions. Published by BMJ.

\section{To cite:}

van Wessem KJP, Leenen LPH. Trauma Surg Acute Care Open 2018;3:e000232.

\begin{abstract}
Background The incidence of acute respiratory distress syndrome (ARDS) has decreased in the last decade by improvement in trauma and critical care. However, it still remains a major cause of morbidity and mortality. This study investigated the current incidence and mortality of ARDS in polytrauma patients.

Methods A 4.5-year prospective study included consecutive trauma patients admitted to a level 1 trauma center intensive care unit (ICU). Isolated head injuries, drowning, asphyxiation, burns, and deaths $<48$ hours were excluded. Demographics, Injury Severity Score (ISS), physiologic parameters, resuscitation parameters, Denver Multiple Organ Failure scores, and ARDS data according to Berlin criteria were prospectively collected. Data are presented as median (IQR), and $p<0.05$ was considered significant.
\end{abstract}

Results 241 patients were included. The median age was 45 (27-59) years, $178(74 \%)$ were male, the ISS was 29 (22-36), and 232 (96\%) patients had blunt injuries. Thirty-one patients (13\%) died. Fifteen patients $(6 \%)$ developed ARDS. The median time to ARDS onset was $3(2-5)$ days after injury. The median duration of ARDS was 2.5 (1-3.5) days. All patients with ARDS were male compared with $61 \%$ of non-ARDS patients $(p=0.003)$. Patients who developed ARDS had higher ISS (30 vs. $25, p=0.01$ ), lower Partial Pressure of Oxygen in arterial blood $\left(\mathrm{PaO}_{2}\right.$, both in the emergency department and ICU, and higher Partial Pressure of Carbon Dioxide in arterial blood $\left(\mathrm{PaCO}_{2}\right)$ in the ICU. Patients with ARDS needed more crystalloids $<24$ hours (8.7 vs. $6.8 \mathrm{~L}$, $p=0.03$ ), received more fresh frozen plasma $<24$ hours ( 3 vs. $0 \mathrm{U}, \mathrm{p}=0.04$ ), and more platelet $<8$ hours and $<24$ hours. Further, they stayed longer on the ventilator (11 vs. 2 days, $p<0.001)$, longer in the ICU ( 12 vs. 3 days, $p<0.001$ ), and in the hospital (33 vs. 15 days, $p=0.004$ ). Patients with ARDS developed more often multiple organ dysfunction syndrome (40\% vs. 3\%, $<<0.001)$ and died more often ( $20 \%$ vs. $3 \%, p=0.01)$. Only one patient with ARDS (7\%) died of ARDS.

Discussion In this polytrauma population mortality was predominantly caused by brain injury. The incidence of ARDS was low; its presentation was only early onset, during a short time period, and accompanied by low mortality.

Level of evidence Level III.

\section{INTRODUCTION}

The first report of acute respiratory distress syndrome (ARDS) in 1967 by Ashbaugh et al ${ }^{1}$ described a clinical syndrome of severe dyspnea, tachypnea, cyanosis refractory to oxygen therapy, loss of lung compliance, and diffuse alveolar infiltrates on chest radiograph.
Once the pathophysiology was elucidated, it became clear that this syndrome was characterized by an increased permeability of the alveolar-capillary barrier, resulting in lung edema with protein-rich fluid causing an impairment in arterial oxygenation. Lung edema and endothelial and epithelial injuries are accompanied by an influx of neutrophils into the interstitium and bronchoalveolar space. Activation and recruitment of neutrophils play an important role in the progression of ARDS. Neutrophils are the first cells to be recruited to the site of inflammation and have a potent antimicrobial defense that includes oxidants, proteinases, and cationic peptides. Under pathologic circumstances, however, unregulated release of these microbicidal compounds into the extracellular space paradoxically can cause damage to the host tissues. Clinical data and animal models have proved the importance of neutrophils in ARDS. ${ }^{2}$

Historically, ARDS has been a significant cause of trauma-related morbidity and mortality, with reported mortality rates up to $40 \% .^{34}$ Many treatment strategies have been created; however, most of them had limited success. ${ }^{5}$ Nowadays, treatment is still limited and mainly consists of supportive mechanical ventilation with low tidal volume and inspiratory pressure ventilation. Therefore, prevention of ARDS is important and identification of risk factors has been subject to many research studies. ${ }^{6-10}$ To early identify patients at risk for ARDS development, several prediction models have been created. Age, Injury Severity Score (ISS), severity of chest injury, crystalloids transfusion, and blood product transfusion have been identified as predictors of ARDS in trauma. ${ }^{7-11}$

With improvement of trauma and critical care, mortality caused by ARDS has decreased in the last years. ${ }^{679-12}$ However, it still uses significant intensive care unit (ICU) resources and remains an important cause of trauma-related deaths.

In contrast to several studies ${ }^{679-12}$ reporting up to 20\% ARDS-related deaths, we did not observe high ARDS incidence and related death rates anymore in our polytrauma population in the last few years. Therefore, we conducted a prospective population-based cohort study in polytrauma patients to investigate the current incidence of ARDS and its contribution to mortality. We hypothesized that both the incidence of ARDS and mortality caused by ARDS were decreased compared with internationally reported data.

\section{METHODS}

\section{Study setting}

The study was conducted at an urban major (level 1) trauma center. From November 2013, a 4.5-year prospective population-based cohort study was 
undertaken including all consecutive trauma patients who were admitted to the ICU of the University Medical Center Utrecht. This major trauma center is the only level 1 trauma center in the province of Utrecht and covers the central region of the Netherlands with a relatively small, but densely populated service area of $1500 \mathrm{~km}^{2}$ and approximately 1.3 million residents. The service area for neurosurgery facilitates 2.1 million residents. Around 1300 trauma patients with full activation of a trauma team are annually admitted. Approximately 375 of them have multiple injuries (ISS >15). ${ }^{13}$ Patients included in the study were all admitted to the ICU either directly from the emergency department (ED) or postoperatively after an urgent surgery was performed. Patients $<15$ years of age, injury caused by asphyxiation, drowning, burns, or isolated traumatic brain injury (TBI) were excluded. Patients who died within 48 hours were excluded as well.

\section{Data collection}

All data were prospectively collected and included patient demographics, ISS, shock, and resuscitation parameters. Admission arterial blood gas analysis, coagulation status, and temperature measurements were performed during resuscitation in the ED as part of standard procedures. Arterial blood gas analysis and temperature measurement were repeated on arrival in the ICU. Urinary output was measured the first hour after arrival in the ICU. Blood product (packed red blood cells, fresh frozen plasma [FFP], and platelets [PLT]) use was recorded in the first 24 hours following admission. The Denver Multiple Organ Failure (MOF) scores and the ARDS Berlin criteria were registered daily up until 28 days or discharge from the ICU. The primary outcome was ARDS development. The secondary outcomes were mortality, ventilator days, ICU length of stay, in-hospital length of stay, and multiple organ dysfunction syndrome (MODS).

\section{Definitions}

ARDS was defined by the Berlin criteria; there are three categories of ARDS based on the degree of hypoxemia and ratio of arterial oxygen partial pressure to fractional inspired oxygen $(\mathrm{PaO} 2 / \mathrm{FiO} 2)$ : grade 1 mild $\left(200<\mathrm{PaO}_{2}: \mathrm{FiO}_{2}\right.$ ratio $\left.\leq 300\right)$, grade 2 moderate $\left(100<\mathrm{PaO}_{2}: \mathrm{FiO}_{2}\right.$ ratio $\left.\leq 200\right)$, and grade 3 severe $\left(\mathrm{PaO}_{2}: \mathrm{FiO}_{2}\right.$ ratio $\left.\leq 100\right)$. Further, bilateral diffuse pulmonary infiltrates (without evidence of heart failure) need to be present on chest X-ray or CT scan. ${ }^{14}$

MODS was defined by the Denver MOF scores of greater than 3 , occurring more than 48 hours after injury. ${ }^{9}$ The Denver MOF score was chosen over Sequential Organ Failure Assessment to avoid difficulties by including the Glasgow Coma Scale (GCS) in the organ failure score. GCS score can be challenging to obtain in the trauma patient in the ICU because patients are often sedated and intubated for extended periods. This could negatively influence the central nervous system (CNS) organ failure score. ${ }^{15}$

Urgent laparotomy was defined as a laparotomy that was performed in patients who were transported from the ED directly (or via CT scan) to the operating room (OR).

\section{Statistical analysis}

Data were analyzed using IBM SPSS Statistics V.25.0. Graphs were prepared with GraphPad Prism V.7.02 (San Diego, CA, USA). Results are presented as median and IQR. Comparison of variables was done using Kruskal-Wallis test or Pearson's $\chi^{2}$ test in dichotomous data. Variables with univariate statistical significance of less than 0.05 were included in a multivariate logistic regression analysis. These variables were analyzed with backward stepwise selection to identify independent risk factors for ARDS and presented as ORs and 95\% CIs. Statistical significance was defined as $\mathrm{p}<0.05$.

\section{RESULTS}

During the 4.5-year study period, 241 trauma patients who were admitted to the ICU and survived 48 hours were included. A hundred and eighteen patients (49\%) were intubated prehospitally, 65 in the ED (27\%), 50 in the OR (21\%), 2 in the ICU $(1 \%)$, and 6 were not intubated at all (2\%). A hundred and twenty $(50 \%)$ of them were directly admitted to the ICU and 121 patients $(50 \%)$ were transported to the OR for surgery straight from the ED and were admitted to the ICU postoperatively. Seventy-four percent of the population were male with a median age of 45 (27-59) years. They sustained predominantly blunt injuries (96\%) and had a median ISS of 29 (22-36). Even though patients with isolated TBI were excluded, the median Abbreviated Injury Scale (AIS) score of the head was 3. ${ }^{1-4}$ Twenty-five percent of patients underwent an urgent laparotomy and 75 (31\%) had a pelvic fracture (table 1$)$.

Patients stayed on the ventilator for 7 (3-12) days. They spend 8 (4-14) days in the ICU and 23 (14-34) days in the hospital. Fifteen patients (6\%) developed ARDS, 76 developed MODS (32\%), and $31(13 \%)$ died (table 1). Death in 24 patients was caused by brain injury (77\%), 3 patients with high cervical spine injury failed to wean from the ventilator (10\%), 1 patient died of MODS (3\%), 1 patient died of sepsis (3\%), 1 patient due to cardiac arrest (3\%), and 1 patient died of ARDS (3\%) after freshwater submersion.

Fifteen patients (6\%) developed ARDS and 66 (27\%) did not develop ARDS nor signs of acute hypoxic respiratory failure (AHRF). The remaining 160 patients all developed some degree of AHRF, but without bilateral infiltrates on chest imaging. Since the presence of bilateral infiltrates is part of the definition of ARDS, these patients were excluded from further analysis.

\section{Subanalysis of patients with ARDS}

Patients who developed ARDS were more often male $(100 \%$ vs. $61 \%, \mathrm{p}=0.003)$. Patients with ARDS had higher ISS (30 [26-41] vs. 25 [19-29], p=0.01) and AIS score of the chest (4 [3-4] vs. 3 [1-3], $\mathrm{p}=0.04)$ than patients who did not develop ARDS (table 1). There was no difference in systolic blood pressure, diastolic blood pressure, temperature, hemoglobin, leukocyte count, and prothrombin time between patients who later developed ARDS and patients who did not (table 2). However, patients who later developed ARDS had lower oxygen levels both on arrival in the ED and ICU, lower $\mathrm{pH}$, higher $\mathrm{PaCo}_{2}$, and lower saturation on arrival in the ICU (table 2). Interestingly, base deficit (BD) was similar between both groups, suggesting the acidosis had a respiratory origin.

There was no difference in intubation location between both groups $(p=0.48)$. Further, future patients with ARDS received more crystalloids $<24$ hours $(8.7$ [5.9-12.8] vs. 6.8 [3.3-9.5] $\mathrm{L}, \mathrm{p}=0.03)$, more units of FFP $<24$ hours $(3[0-4]$ vs. $0[0-2]$ $\mathrm{U}, \mathrm{p}=0.04)$, and more PLT $<8$ hours $(0[0-1]$ vs. $0[0-0] \mathrm{U}$, $\mathrm{p}=0.01)$ and $<24$ hours $(0[0-2]$ vs. 0 [0-0] $U, p=0.02$; table 1$)$. Patients with ARDS developed MODS more often than patients without ARDS (40\% vs. $2 \%, \mathrm{p}<0.001$; table 1 ). They stayed longer on the ventilator $(11$ [6-17] vs. 2 [1-3] days, $\mathrm{p}<0.001)$, in the ICU $(12$ [8-19] vs. 3 [2-4] days, p<0.001), and in the hospital (33 [14-43] vs. 15 [10-23] days, $\mathrm{p}<0.001)$. Patients who developed ARDS died more often $(20 \%$ vs. $3 \%, \mathrm{p}=0.01$; 
Table 1 Patient demographics, resuscitation, and outcome parameters

\begin{tabular}{|c|c|c|c|c|}
\hline & $\begin{array}{l}\text { Total cohort } \\
(\mathrm{n}=241)\end{array}$ & $\begin{array}{l}\text { No ARDS } \\
(\mathrm{n}=66)\end{array}$ & $\begin{array}{l}\text { ARDS } \\
(n=15)\end{array}$ & $P$ value \\
\hline \multicolumn{5}{|l|}{ Demographics } \\
\hline Age (years) & $45(27-59)$ & $37(23-56)$ & $38(25-58)$ & 0.67 \\
\hline Gender ( $\%$ male) & $178(74)$ & $40(61)$ & $15(100)$ & $0.003^{*}$ \\
\hline MOI (\% blunt) & $232(96)$ & $62(94)$ & $15(100)$ & 0.33 \\
\hline ISS & $29(22-36)$ & $25(19-29)$ & $30(26-41)$ & $0.01^{*}$ \\
\hline AIS head & $3(1-4)$ & $3(0-4)$ & $2(0-4)$ & 0.13 \\
\hline AIS face & $0(0-2)$ & $0(0-1)$ & $0(0-2)$ & 0.70 \\
\hline AIS chest & $3(2-4)$ & $3(1-3)$ & $4(3-4)$ & $0.04^{*}$ \\
\hline AIS abdomen & $1(0-3)$ & $1(0-2)$ & $2(0-3)$ & 0.57 \\
\hline $\begin{array}{l}\text { AIS extremities/ } \\
\text { pelvis }\end{array}$ & $2(1-3)$ & $2(0-3)$ & $3(0-3)$ & 0.20 \\
\hline AIS external & $0(0-1)$ & $0(0-1)$ & $1(0-1)$ & 0.62 \\
\hline Pelvic fracture & $75(31)$ & $21(32)$ & $4(27)$ & 0.70 \\
\hline Urgent laparotomy & $61(25)$ & $16(24)$ & $6(40)$ & 0.22 \\
\hline \multicolumn{5}{|l|}{ Resuscitation } \\
\hline \multicolumn{5}{|l|}{ Crystalloids (L) } \\
\hline$<8$ hours & $4.7(2.6-6.5)$ & $4.5(1.5-5.9)$ & $4.9(2.0-7.0)$ & 0.33 \\
\hline$<24$ hours & $7.6(5.3-10.4)$ & $6.8(3.3-9.5)$ & $8.7(5.9-12.8)$ & $0.03^{*}$ \\
\hline \multicolumn{5}{|l|}{ PRBC (U) } \\
\hline$<8$ hours & $1(0-4)$ & $0(0-3)$ & $3(0-7)$ & 0.18 \\
\hline$<24$ hours & $1(1-6)$ & $1(0-3)$ & $3(0-9)$ & 0.24 \\
\hline \multicolumn{5}{|l|}{$\operatorname{FFP}(U)$} \\
\hline$<8$ hours & $0(0-4)$ & $0(0-2)$ & $2(0-4)$ & 0.05 \\
\hline$<24$ hours & $0(0-5)$ & $0(0-2)$ & $3(0-4)$ & $0.04^{*}$ \\
\hline \multicolumn{5}{|l|}{ PLT (U)† } \\
\hline$<8$ hours & $0(0-0)$ & $0(0-0)$ & $0(0-1)$ & $0.01^{*}$ \\
\hline$<24$ hours & $0(0-1)$ & $0(0-0)$ & $0(0-2)$ & $0.02^{*}$ \\
\hline \multicolumn{5}{|l|}{ Outcome } \\
\hline Ventilator days & $7(3-12)$ & $2(1-3)$ & $11(6-17)$ & $<0.001^{*}$ \\
\hline ICU-LOS (days) & $8(4-14)$ & $3(2-4)$ & $12(8-19)$ & $<0.001^{*}$ \\
\hline H-LOS (days) & $23(14-34)$ & $15(10-23)$ & $33(14-43)$ & $0.004^{*}$ \\
\hline MODS & $76(32)$ & 2 (3) & $6(40)$ & $<0.001^{*}$ \\
\hline Mortality & $31(13)$ & $2(3)$ & $3(20)$ & $0.01 *$ \\
\hline
\end{tabular}

Data are expressed as median (IQR) or absolute number (\%).

*Statistically significant.

†1 unit of platelets contains five donors.

AIS, Abbreviated Injury Scale; ARDS, Acute Respiratory Dysfunction Syndrome;

FFP, fresh frozen plasma; H-LOS, hospital length of stay;ICU-LOS, intensive care unit length of stay; ISS, Injury Severity Score; MODS, Multiple Organ Dysfunction Syndrome; MOI, mechanism of injury; PLT, platelet; PRBC, packed red blood cells.

table 1). Eight of 15 patients with ARDS developed grade 3 severe ARDS and 7 developed grade 2 moderate ARDS.

In multivariate analysis only MODS, $\mathrm{PaO}_{2}$ in the ICU, and crystalloids $<24$ hours were independent predictors of ARDS (table 3). Additionally, a stepwise logistic regression with backward selection (parameters out if $\mathrm{p}<0.05$ ) was performed. The backward stepwise logistic regression showed the highest Nagelkerke R square (0.61) if all parameters were included.

Time to ARDS onset was early after trauma; ARDS developed $3(2-5)$ days from injury with a length of 2.5 (1-3.5) days (figure 1). Six patients had ARDS for more than 3 days and five patients had ARDS for more than 3 consecutive days (figure 2).

The incidence of ARDS decreased over time even though ISS did not change in this period. In the first year of the studied
Table 2 ED and ICU parameters comparing patients who developed ARDS and patients who did not

\begin{tabular}{|c|c|c|c|}
\hline & $\begin{array}{l}\text { No ARDS } \\
(n=66)\end{array}$ & $\begin{array}{l}\text { ARDS } \\
(n=15)\end{array}$ & $P$ value \\
\hline \multicolumn{4}{|l|}{ ED parameters } \\
\hline $\mathrm{SBP}(\mathrm{mm} \mathrm{Hg})$ & $125(110-137)$ & $114(105-136)$ & 0.58 \\
\hline $\mathrm{DBP}(\mathrm{mm} \mathrm{Hg})$ & $78(65-85)$ & 70 (59-90) & 0.47 \\
\hline $\mathrm{Hb}(\mathrm{mmol} / \mathrm{L})$ & $8.2(7.5-9.0)$ & $8.0(7.0-9.5)$ & 0.68 \\
\hline Leukocytes $\left(\times 10^{9} / \mathrm{L}\right)$ & $15.9(11.2-19.8)$ & $20.4(11.4-22.4)$ & 0.82 \\
\hline Platelets (x109/L) & 249 (203-296) & $227(191-251)$ & 0.19 \\
\hline PT & $15.1(14.3-17.1)$ & $17.6(14.4-21.6)$ & 0.06 \\
\hline $\mathrm{pH}$ & 7.34 (7.29-7.39) & $7.30(7.24-7.37)$ & 0.21 \\
\hline $\mathrm{PaCO}_{2}(\mathrm{~mm} \mathrm{Hg})$ & $44(39-50)$ & $48(42-53)$ & 0.10 \\
\hline $\mathrm{PaO}_{2}(\mathrm{~mm} \mathrm{Hg})$ & $259(126-356)$ & $186(79-254)$ & $0.03^{*}$ \\
\hline $\mathrm{BD}(\mathrm{mmol} / \mathrm{L})$ & $2.0(0.5-6.0)$ & $4.0(0.0-6.0)$ & 0.59 \\
\hline Saturation (\%) & $100(99-100)$ & $100(94-100)$ & 0.12 \\
\hline \multicolumn{4}{|l|}{ ICU parameters } \\
\hline $\mathrm{SBP}(\mathrm{mm} \mathrm{Hg})$ & $123(108-137)$ & 134 (110-146) & 0.24 \\
\hline $\mathrm{DBP}(\mathrm{mm} \mathrm{Hg})$ & 68 (54-78) & $62(50-70)$ & 0.11 \\
\hline Temperature $\left({ }^{\circ} \mathrm{C}\right)$ & $35.2(34.5-35.9)$ & $35.9(34.9-36.2)$ & 0.96 \\
\hline $\mathrm{Hb}(\mathrm{mmol} / \mathrm{L})$ & $7.7(6.8-8.5)$ & $7.3(6.5-7.9)$ & 0.47 \\
\hline $\mathrm{pH}$ & $7.34(7.32-7.40)$ & $7.30(7.26-7.36)$ & $0.04^{*}$ \\
\hline $\mathrm{PaCO}_{2}(\mathrm{~mm} \mathrm{Hg})$ & $42(37-46)$ & $49(44-56)$ & $0.002^{*}$ \\
\hline $\mathrm{PaO}_{2}(\mathrm{~mm} \mathrm{Hg})$ & 173 (127-196) & $116(94-160)$ & $0.002^{*}$ \\
\hline $\mathrm{BD}(\mathrm{mmol} / \mathrm{L})$ & $2.5(0.5-5.9)$ & $2.8(1.2-5.5)$ & 0.78 \\
\hline Sat $(\%)$ & 99 (98-99) & 98 (95-99) & $0.003^{*}$ \\
\hline UO (mL) & $125(80-300)$ & $78(40-235)$ & 0.11 \\
\hline
\end{tabular}

Data are expressed as median (IQR).

*Statistically significant.

ARDS, acute respiratory distress syndrome; BD, Base Deficit; DBP, diastolic blood pressure; $E D$, emergency department; $H b$, hemoglobin; ICU, intensive care unit; PT, prothrombin time; PaCO2, Partial Pressure of Carbon Dioxide in Arterial Blood; $\mathrm{PaO2}$, Partial Pressure of Oxygen in Arterial Blood; SBP, systolic blood pressure; Sat, saturation; UO, urinary output first hour in ICU.

period, 43 polytrauma patients were included, of whom 7 (16\%) developed ARDS, whereas in the following years the incidence of ARDS decreased to approximately 5\% in 2015 and 2016, and even further to $3.7 \%$ and $3.0 \%$, respectively, in 2017 and in the first 6 months in 2018 (figure 3).

\begin{tabular}{|c|c|c|c|c|}
\hline Variable & $\beta$ coefficient & $P$ value & OR & $95 \% \mathrm{Cl}$ \\
\hline ISS & 0.055 & 0.210 & 1.056 & 0.970 to 1.151 \\
\hline MODS & 2.676 & $0.023^{*}$ & 14.531 & 1.436 to 146.986 \\
\hline Als_Chest & 0.299 & 0.496 & 1.257 & 0.651 to 2.428 \\
\hline $\mathrm{PaO}_{2-} \mathrm{ED}$ & 0.001 & 0.847 & 1.001 & 0.993 to 1.009 \\
\hline $\mathrm{PaCO}_{2} \mathrm{ICU}$ & -0.022 & 0.235 & 0.978 & 0.944 to 1.014 \\
\hline $\mathrm{PaO}_{2} \_\mathrm{ICU}$ & -0.038 & $0.021^{*}$ & 0.963 & 0.933 to 0.994 \\
\hline FFP $<24$ hours & -0.107 & 0.328 & 0.898 & 0.725 to 1.113 \\
\hline Crystalloids $<24$ hours & 0.000 & $0.026^{*}$ & 1.000 & 1.000 to 1.001 \\
\hline Constant & -0.391 & 0.861 & 0.676 & \\
\hline
\end{tabular}

*Statistically significant.

AIS, Abbreviated Injury Score; ARDS, acute respiratory distress syndrome; ED, emergency department; FFP, fresh frozen plasma; ICU, intensive care unit; ISS, Injury Severity Scale; MODS, multiple organ dysfunction syndrome. 


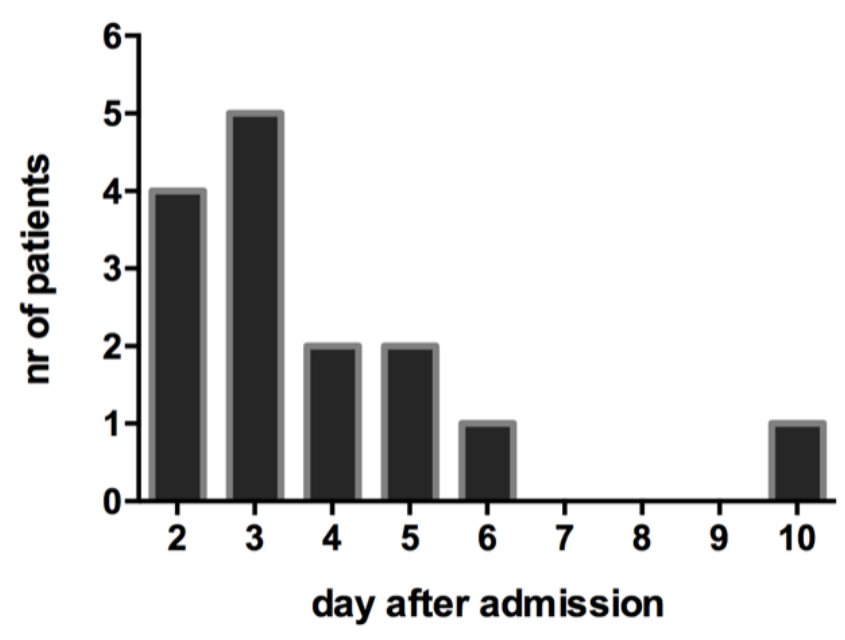

Figure 1 Day of acute respiratory distress syndrome onset.

Only 1 of 15 patients with ARDS (7\%) died of ARDS. He developed severe ARDS (lowest $\mathrm{PaO}_{2}: \mathrm{FiO}_{2}$ ratio was 40) 3 days after massive aspiration after freshwater submersion after a motor vehicle crash with brain injury and several cervical spine fractures. He had ARDS for 4 days with the lowest $\mathrm{PaO}_{2}: \mathrm{FiO}_{2}$ ratio of 40, and despite venovenous extracorporeal life support he died 7 days after admission. Further, two other patients died while having ARDS; one patient suffered from multiple injuries including severe brain injury and treatment was withdrawn as it was considered medically futile. The other patient failed to wean from the ventilator after $\mathrm{C} 2$ cervical spine injury with myelum contusion resulting in tetraplegia.

\section{DISCUSSION}

In this population of severely injured patients, the incidence of ARDS was 6\%. Only one patient with ARDS died of ARDS (7\%). Patients with ARDS still used significantly more resources than non-ARDS patients, with longer ventilator days and more days in the ICU and in the hospital. In this cohort of severely injured polytrauma patients, the incidence of ARDS was low and the length of ARDS was decreased with low ARDS-related mortality.

The overall in-hospital mortality was $17 \%$ and predominantly caused by brain injury and/or spinal cord injury. This mortality rate is comparable with reports in the literature; however, the percentage of brain/spinal cord injury-related deaths was higher than most reports about cause of death in polytrauma. ${ }^{16} 17$ This could be partly explained by the fact that our level 1 trauma center is the only referral center for brain and spinal cord injury in the state. ${ }^{13}$

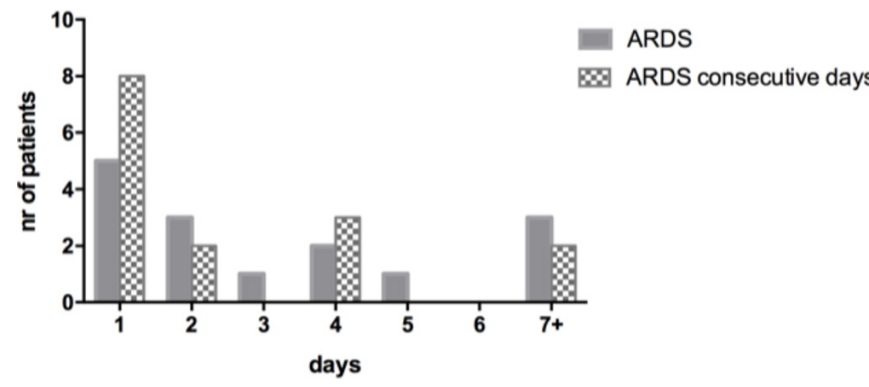

Figure 2 Duration of acute respiratory distress syndrome (ARDS) measured in total days during admission and in consecutive days.

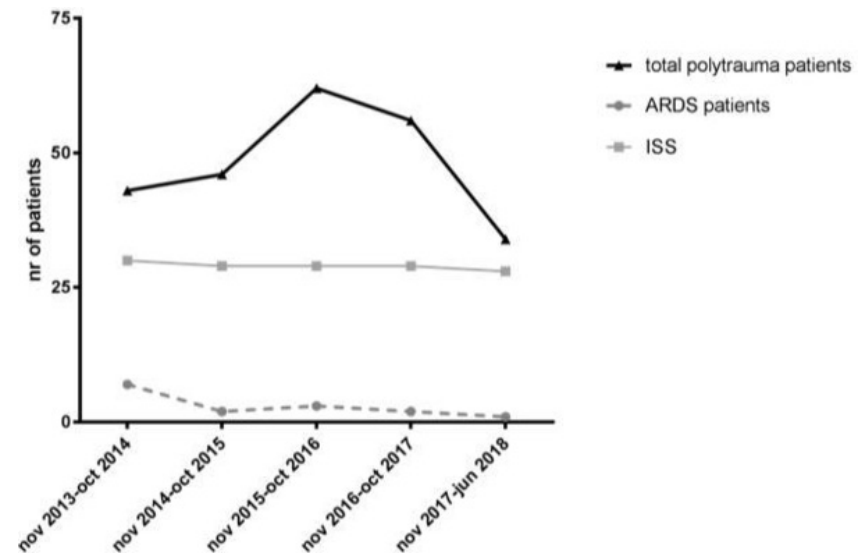

Figure 3 Incidence of acute respiratory distress syndrome (ARDS) in time related to Injury Severity Score (ISS).

To clarify low ARDS mortality rates, one could debate that patients did not die of ARDS because they already died due to brain injury. However, time to death was 9 (7-16) days and time to ARDS onset was 3 days with a length of 2.5 days. Further, besides one patient who died of ARDS, only two other deceased died while having ARDS. Generally, ARDS was treated before the patients died, so this does not explain the low ARDS mortality rates in our cohort.

Both the incidence of ARDS and ARDS-related mortality in our cohort were lower than other reported studies. ${ }^{1012} 18$ Further, the duration of ARDS was short (median 2.5 days), with 7 days on the ventilator and 8 days in ICU. This is also lower compared with other studies. ${ }^{10} 1218$

This studied population was different compared with most North American studies; our cohort almost exclusively consisted of blunt injuries caused by motor vehicle crash and falls from height in a relatively small service area with short transport times. In this polytrauma population parameters such as blood pressure and hemoglobin were within normal ranges on arrival in the ED. One could argue that these patients were not severely injured at all. This is contradicted by the fact that patients were mildly acidotic and coagulopathic on arrival. Further, they had an ISS of $29,31 \%$ had a pelvic fracture, $25 \%$ needed an urgent laparotomy, $11 \%$ received massive transfusion, and they were all admitted to the ICU since that was one of the inclusion criteria. The studied cohort included the sickest trauma patients admitted to our major trauma center. This phenomenon in which severely injured patients in smaller service areas with short transport times do not have deranged physiologic parameters on arrival in the ED has been described earlier. ${ }^{19} 20$ These patients do not have the time to deteriorate, because they are in the hospital before blood pressure, BD, and hemoglobin will change distinctly. This early reversal of shock however does not prevent the development of ARDS. Possibly, it does explain the attenuation of the syndrome. It is likely that this attenuation of ARDS could also be attributed by a combination of several improvements in trauma and critical care in the last decades, such as improved prehospital care, hemostatic resuscitation, damage control surgery, and lung protective ventilation.

Many research groups have identified predictors for ARDS such as age, ISS, and resuscitation parameters. ${ }^{1012}{ }^{12-23}$ Predictors for ARDS in this study were $\mathrm{PaO}_{2}$ in the ICU, administration of crystalloids < 24 hours, and MODS. Patients who developed ARDS received more crystalloids and blood products. This is consistent with previously published studies demonstrating 
increased risk of ARDS with increasing blood product transfusions. ${ }^{10}{ }^{12}$ Moreover, this study identifies FFP administration as an independent risk factor for ARDS development. Since FFP and more aggressive blood product utilization may be among the reasons why there are more survivors, there may be a survival bias. Predictors are tools to identify patients at risk for ARDS, but do not explain causal mechanisms, so association does not necessarily mean causation.

One of the limitations of this study is that it was conducted at a single institution in which the clinical treatment and research were conducted by the same clinicians. Another limitation is that patients with isolated head injuries were excluded because of possible different physiologic response to trauma, although we did include polytrauma patients who had associated head injuries. We chose to include these patients since many of our severely injured patients have associated brain injury and they are also prone to ARDS.

In conclusion, in this cohort of severely injured patients, the incidence of ARDS was low, and its characteristics have fundamentally changed to an entity that only has an early onset, shorter time period, and less severe expression with lower mortality than previously reported. This attenuation of the deadly ARDS to a less deleterious disposition could be considered a success of the improvements in trauma and critical care in the last decade.

Contributors KJPvW and LPHL have contributed to the conception and design of the study. KJPvW has prospectively collected data. KJPvW and LPHL have done the analysis and interpretation of data. KJPvW has drafted the article. LPHL has revised it critically for important intellectual content. LPHL has given final approval of the version to be submitted.

Competing interests None declared.

Patient consent Not required.

Ethics approval The ethics committee of University Medical Center Utrecht approved this prospective observational study (reference number WAG/ $\mathrm{mb} / 16 / 026664)$.

Provenance and peer review Not commissioned; internally peer reviewed.

Data sharing statement The data set generated and analyzed during the current study is available from the corresponding author on reasonable request.

Open access This is an open access article distributed in accordance with the Creative Commons Attribution Non Commercial (CC BY-NC 4.0) license, which permits others to distribute, remix, adapt, build upon this work non-commercially, and license their derivative works on different terms, provided the original work is properly cited, appropriate credit is given, any changes made indicated, and the use is non-commercial. See: http://creativecommons.org/licenses/by-nc/4.0/.

\section{REFERENCES}

1. Ashbaugh DG, Bigelow DB, Petty $T L$, Levine BE. Acute respiratory distress in adults. Lancet 1967;2:319-23.

2. Grommes J, Soehnlein 0. Contribution of neutrophils to acute lung injury. Mol Med 2011;17:1-307.
3. Ciesla DJ, Moore EE, Johnson JL, Cothren CC, Banerjee A, Burch JM, Sauaia A. Decreased progression of postinjury lung dysfunction to the acute respiratory distress syndrome and multiple organ failure. Surgery 2006;140:640-8.

4. Salim A, Martin M, Constantinou C, Sangthong B, Brown C, Kasotakis G, Demetriades

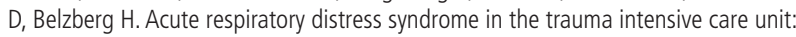
morbid but not mortal. Arch Surg 2006;141:655-8.

5. Fan E, Brodie D, Slutsky AS. Acute respiratory distress syndrome: advances in diagnosis and treatment. JAMA 2018:319:698-710

6. Park PK, Cannon JW, Ye W, Blackbourne LH, Holcomb JB, Beninati W, Napolitano LM, Incidence NLM. Incidence, risk factors, and mortality associated with acute respiratory distress syndrome in combat casualty care. J Trauma Acute Care Surg 2016;81(Suppl 2):S150-S156.

7. Robinson BRH, Cohen MJ, Holcomb JB, Pritts TA, Gomaa D, Fox EE, Branson RD, Callcut RA, Cotton BA, Schreiber MA, et al. Risk factors for the development of acute respiratory distress syndrome following hemorrhage. Shock 2018:50:258-64.

8. Miller PR, Croce MA, Kilgo PD, Scott J, Fabian TC. Acute respiratory distress syndrome in blunt trauma: identification of independent risk factors. Am Surg 2002;68:845-50

9. Zielinski MD, Jenkins D, Cotton BA, Inaba K, Vercruysse G, Coimbra R, Brown CV, Alley DE, DuBose J, Scalea TM, et al. Adult respiratory distress syndrome risk factors for injured patients undergoing damage-control laparotomy: AAST multicenter post hoc analysis. J Trauma Acute Care Surg 2014;77:886-91.

10. Daher P, Teixeira PG, Coopwood TB, Brown LH, Ali S, Aydelotte JD, Ford BJ, Hensely AS, Brown CV. Mild to moderate to severe: What drives the severity of ARDS in trauma patients? Am Surg 2018:84:808-12.

11. Daurat A, Millet I, Roustan JP, Maury C, Taourel P, Jaber S, Capdevila X, Charbit J. Thoracic Trauma Severity score on admission allows to determine the risk of delayed ARDS in trauma patients with pulmonary contusion. Injury 2016;47:147-53.

12. O'Leary MP, Keeley JA, Yule A, Suruki C, Plurad DS, Moazzez A, Neville AL, Putnam BA, Kim DY. Clinical predictors of early acute respiratory distress syndrome in trauma patients. Am J Surg 2016;212:1096-100.

13. Gunning AC, Lansink KW, van Wessem KJ, Balogh ZJ, Rivara FP, Maier RV, Leenen LP. Demographic patterns and outcomes of patients in Level I trauma centers in three international trauma systems. World J Surg 2015;39:2677-84.

14. Ranieri VM, Rubenfeld GD, Thompson BT. ARDS Definition Task Force. Acute respiratory distress syndrome: the Berlin Definition. JAMA 2012;307:2526-33.

15. Dewar DC, White A, Attia J, Tarrant SM, King KL, Balogh ZJ. Comparison of postinjury multiple-organ failure scoring systems: denver versus sequential organ failure assessment. J Trauma Acute Care Surg 2014;77:624-9.

16. Evans JA, van Wessem KJ, McDougall D, Lee KA, Lyons T, Balogh ZJ. Epidemiology of traumatic deaths: comprehensive population-based assessment. World I Surg 2010;34:158-63.

17. Pfeifer R, Tarkin IS, Rocos B, Pape HC. Patterns of mortality and causes of death in polytrauma patients--has anything changed? Injury 2009;40:907-11.

18. Fahr $M$, Jones $G, O^{\prime} N$ Neal $H$, Duchesne J, Tatum $D$. Acute respiratory distress syndrome incidence, but not mortality, has decreased nationwide: a national trauma data bank study. Am Surg 2017;83:323-31.

19. Gunning AC, Leenen LP. Applicability of the predictors of the historical trauma score in the present Dutch trauma population: modelling the TRISS predictors. I Trauma Acute Care Surg 2014;77:614-9.

20. van Wessem KJP, Leenen LPH. Reduction in mortality rates of postinjury multiple organ dysfunction syndrome: a shifting paradigm? A prospective population-based cohort study. Shock 2018:49:33-8.

21. Wu J, Sheng L, Ma Y, Gu J, Zhang M, Gan J, Xu S, Jiang G. The analysis of risk factors of impacting mortality rate in severe multiple trauma patients with posttraumatic acute respiratory distress syndrome. Am J Emerg Med 2008:26:419-24.

22. Watkins TR, Nathens AB, Cooke CR, Psaty BM, Maier RV, Cuschieri J, Rubenfeld GD. Acute respiratory distress syndrome after trauma: development and validation of a predictive model. Crit Care Med 2012;40:2295-303.

23. Afshar M, Smith GS, Cooper RS, Murthi S, Netzer G. Trauma indices for prediction of acute respiratory distress syndrome. J Surg Res 2016;201:394-401. 